\title{
Solution aging and degradation of a transparent conducting polymer dispersion
}

\author{
Jun Li ${ }^{\mathrm{a}}$, Ian E. Jacobs ${ }^{\mathrm{a}}$, Stephan Friedrich ${ }^{\mathrm{b}}$, Pieter Stroeve ${ }^{\mathrm{a}}$, Adam J. Moulé, \\ ${ }^{a}$ Chemical Engineering and Materials Science, University of California, Davis, CA 95616, USA \\ ${ }^{b}$ Advanced Detector Group, Lawrence Livermore National Laboratory, Livermore, CA 94550, USA
}

\begin{abstract}
As organic electronics improve, there is increased research interest on the longevity and stability of both the device and individual material components. Most of these studies focus on post deposition degradation and aging of the film. In this article, we examine the stability of polyelectrolyte dispersions before film coating. We observe substantial differences in the solution properties of the transparent conducting polymer, S-P3MEET, when comparing fresh versus aged dispersions and relate these solution differences to film properties. The aged dispersion contains large agglomerates and exhibits a typical shear-thinning rheological behavior, which results in non-uniformity of the spin-coated films. Near edge X-ray absorption fine structure measurements were used to differentiate the changes in bonding and oxidation states and show that aged S-P3MEET is more highly self-doped than fresh SP3MEET. We also show that addition of acid, salt or heat to fresh S-P3MEET can accelerate the degradation/aging process but are subjected to different mechanisms. Conductivity measurements of S-P3MEET films illustrate that there is a tradeoff between increased work function and decreased conductivity upon perfluorinated ionomer (PFI) loading. The formation of nanostructure in solution is also correlated to film morphology variations obtained from atomic force microscopy. We expect that dispersion aging is a process that commonly exists in most solution-dispersed polyelectrolyte materials and that the methodologies presented in this paper might be beneficial to future degradation/stability studies.
\end{abstract}

Keywords:

Organic electronics; Solution processing; Stability; Degradation; Aging; Conductivity;

\section{Introduction}

There has been considerable interest in the development of solution processed organic electronic devices, such as organic photovoltaics (OPV) and organic light emitting diodes (OLED), as they show potential as low-cost alternatives compared to their inorganic counterparts [1,2]. Although device efficiency continues to improve $[3,4,5]$, relatively little attention has been paid to the stability and longevity of these devices and related materials. An extensive study on the degradation/aging process is a prerequisite to develop a useful commercial technology $[6,7]$.

Organic electronic devices are commonly fabricated by solution processing, as shown in Fig. 1. Dissolved materials are either coated or printed onto substrates to form continuous films and device structures [8]. Various factors have been reported that lead to device degradation. Based on the origin, two types of degradation mechanism are possible. First, extrinsic degradation is the chemical and/or physical changes induced by external triggers. For example, OPV devices with active layers composed of poly(phenylene vinylene) (PPV) or poly(3hexylthiophene-2,5-diyl) (P3HT) have been shown to be susceptible to degradation by water and oxygen $[9,10,11]$. In addition, extrinsic degradation can also occur when exposing devices to UV light $[12,13]$, elevated temperatures [14, 15], high

${ }^{*}$ Corresponding author, Phone: +01 530 754-8669, Fax: +01 530 752-1074

Email address: amoule@ucdavis . edu (Adam J. Moulé) drive current [16], etc. Intrinsic degradation, on the other hand, results from factors that are built into the device, such as interfacial instability, molecular diffusion, phase separation, or reaction between components. Interfacial reactions, for instance, have been observed at the metal electrodes (e.g. Al)/active layer interface [17, 18, 19] as well as the PEDOT:PSS/active layer interface $[20,21,22]$. Recent research reveals that phase separation and/or diffusion of small organic molecules, such as fullerenes [23, 24] and molecular dopants [25, 26, 27], may also

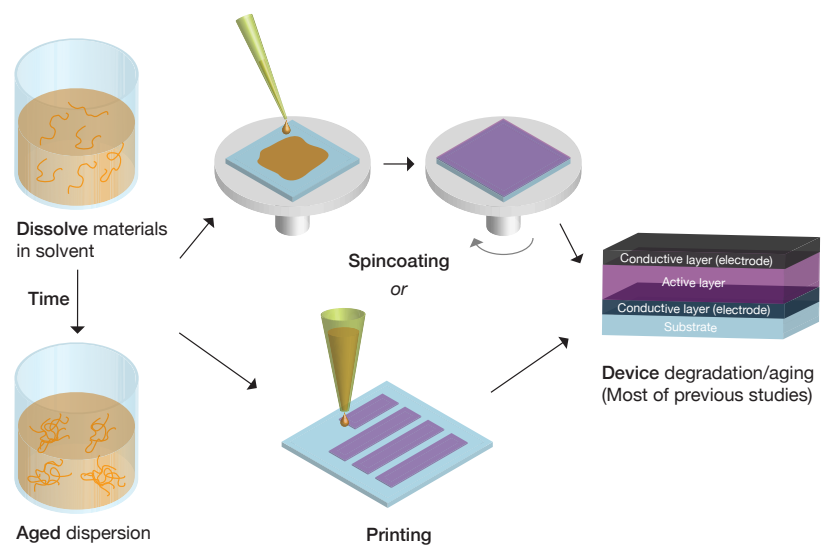

Figure 1: Schematic of solution process and dispersion degradation/aging. 
affect device stability [28]. Furthermore, it is widely accepted that intrinsic degradation can be accelerated by external environmental factors [29].

Most of these degradation/aging studies focus on the post deposition films and devices. However, contributions to degradation/aging processes which occur upstream of the end product should also be considered. Researchers frequently purchase illdefined solutions (e.g. PEDOT:PSS or photoactive inks) and assume that they will maintain desired properties until replacement with a new batch. We will show here that this is not a good assumption. Some solutions are intrinsically unstable or can be triggered extrinsically to aggregate [30,31], shown in Fig. 1. We posit that the aging of solutions can contribute to inconsistent results published in different groups [32] and even within the same group and even when the same sample preparation procedures and experimental conditions are precisely controlled. The solution stability is crucial in most of solution-processed systems and will considerably affect the film morphology and thus the device performance [33]. Therefore, degradation/aging studies on polymer dispersions are necessary. Although degradation and stabilization problems related to polymer dispersions are known for years [34, 35], in the field of transparent conducting polymers or polyelectrolytes, relatively few solution stability studies have been published to the best of our knowledge [36].

In this work, we will investigate the solution stability of a transparent conductive polymer, poly(thiophene-3-[2-(2methoxy-ethoxy)ethoxy]-2,5-diyl) (S-P3MEET) (Fig. 2). SP3MEET was chosen (1) because S-P3MEET is a self-doped (meaning, oxidatively doped) polymer and its immobile sulfonate moieties will not cause unintended phase separation compared with PEDOT:PSS [37] and (2) because self-doped at reduced $\mathrm{pH}$ alternatives to PEDOT:PSS are increasingly sought for the specific purpose of increased device performance as well as lifetime [38, 39]. Recently, we showed that similar to PEDOT:PSS where the work function can be altered using secondary dopants $[40,41]$, the work function of S-P3MEET can also be tuned via the addition of a perfluorinated ionomer (PFI)

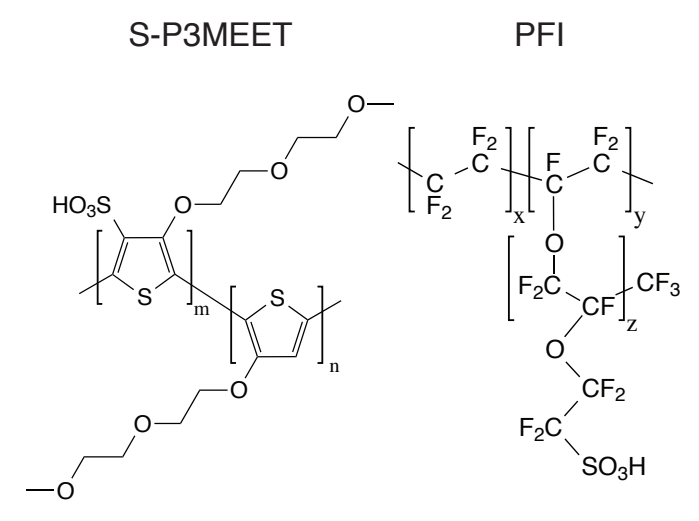

Figure 2: Chemical structures of S-P3MEET (left) and fluorinated additive PFI (right).
(Fig. 2) [42]. In this study, we define doping as any and all redox processes that occur between the conjugated polymer backbone and other media, which can be internal groups (e.g. sulfonate moieties in the S-P3MEET) and external reactants (e.g. acidic additive). In addition, we also name the S-P3MEET that has been stored in the solution state (in the dark in a sealed container at $5{ }^{\circ} \mathrm{C}$ ) for one year as aged S-P3MEET in order to differentiate it from its fresh counterpart. We will use particle size, zeta potential and rheological measurements to characterize the solution properties and aggregation of the polymer dispersions. A systematic comparison of these properties with their oxidation states is used to define the mechanism of aging. Comparative additive and heating experiments are also conducted to reveal the origin of this degradation/aging process. Finally, we return to externally blend S-P3MEET with acidic PFI and address the concern that mixed S-P3MEET films might be rendered unstable by the presence of the PFI. Therefore, PFI concentrationdependent conductivity and morphology of S-P3MEET films are also thoroughly investigated.

\section{Materials and Methods}

\subsection{Materials and Sample Preparation}

The S-P3MEET (Plexcore OC RG-1100) was provided by Plextronics, inc. The aged S-P3MEET used has been stored in the refrigerator in the dark for 12 months without external stimulations. A single batch of S-P3MEET was used for all work in this study. PFI (Liquion LG-1115) was purchased from Nafion Store. PEDOT:PSS (Clevios P VP Al 4083) was purchased from Heraeus. All chemicals were used as-received unless otherwise indicated.

For sample preparation, all substrates were rinsed using ultrasonic baths of acetone, $5 \%$ mucasol solution, and deionized water, successively, followed by nitrogen drying. The substrates were then exposed to UV/ozone for $30 \mathrm{~min}$ before use. Solutions of S-P3MEET and PFI were mixed in appropriate ratios to reach the desired loading levels. The blend solutions were then diluted using a solvent mixture that consisted of $50 \%$ isopropyl alcohol, 40\% 1,3-propanediol, and 10\% deionized water by volume (IPW solvent mixture). The films were spincoated on clean substrates from blend solutions, and placed on a hot plate set to $110^{\circ} \mathrm{C}$ for 3 minutes to remove residual solvent.

\subsection{Characterization}

Particle size and zeta potential were measured using a Zetasizer Nano ZS (Malvern Instruments). For the additive experiments, $0.05 \mathrm{~mL}$ of $1.0 \mathrm{M} \mathrm{HCl}, \mathrm{NaOH}$ or $\mathrm{NaCl}$ was added into a $1 \mathrm{~mL}$ fresh S-P3MEET solution. For the heating experiment, the fresh S-P3MEET solution was heated at $110^{\circ} \mathrm{C}$ for 10 hours in a sealed container. All samples were diluted using the IPW solvent mixture described above and measurements were performed at $25^{\circ} \mathrm{C}$. A minimum of three measurements were performed for each sample.

Rheological measurements were performed at $25^{\circ} \mathrm{C}$ using a AR 1000-N rheometer (TA Instruments) with a cone and plate 
geometry. A minimum of three measurements were also performed for each sample.

Near edge X-ray absorption fine structure (NEXAFS) measurements were performed on beamline 6.3.1 at the Advanced Light Source (ALS) at Lawrence Berkeley National Laboratory (LBNL). S-P3MEET films were spin-coated onto ITO-coated glass substrates. The total electron yield (TEY) carbon K-edge spectra of the samples were obtained at a $\sim 30^{\circ}$ incidence angle using a Galileo 4716 channeltron electron multiplier. The spectra were processed and analyzed using Athens software. The TEY signal was normalized by the incident beam intensity $\mathrm{I}_{0}$ and a linear background was subtracted. All the spectra were normalized above the absorption edge at $320 \mathrm{eV}$.

For in-plane conductivity measurements, a four-point probe setup was used. Four electrodes $(5 \mathrm{~nm} \mathrm{Cr} / 95 \mathrm{~nm} \mathrm{Au}, 1 \times 5$ $\mathrm{mm}^{2}, 1 \mathrm{~mm}$ spacing) were thermally evaporated on clean glass substrates. Films were then spin-coated and measured using a Keithely 2420 sourcemeter. For out-of-plane conductivity measurement, the bottom electrode $(5 \mathrm{~nm} \mathrm{Cr} / 95 \mathrm{~nm} \mathrm{Au}, 5 \times 15$ $\mathrm{mm}^{2}$ ) was first deposited on the substrate. After spin-coating the films, $100 \mathrm{~nm} \mathrm{Au}$ was then deposited as the top electrode using the same shadow mask to provide an active area of 0.35 $\mathrm{cm}^{2}$. All conductivity measurements were performed in the dark under $\mathrm{N}_{2}$ atmosphere in a glovebox.

Tapping-mode atomic force microscopy (TM-AFM) measurements were performed using a Veeco Multimode microscope. Silicon probes (Tap300Al-G) with a resonant frequency of $300 \mathrm{kHz}$ and a force constant of $40 \mathrm{~N} / \mathrm{m}$ were used for imaging. Images were processed and analyzed using the Veeco NanoScope Analysis software.

\section{Results and Discussion}

\subsection{Aging of the S-P3MEET Dispersion}

Issues with performance consistency using S-P3MEET from our previous studies motivate this study $[42,43]$. We now believe that solution aging is the source of the previous inconsistency. In order to unveil the mechanism of solution aging,

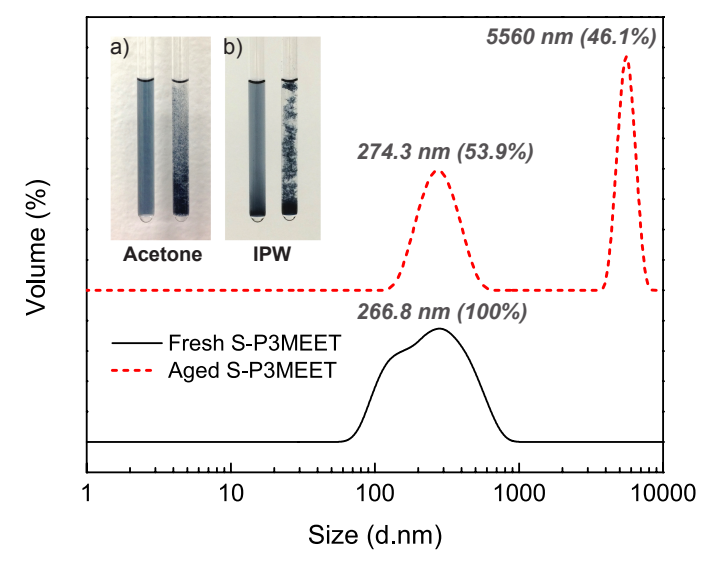

Figure 3: Particle size distributions of fresh (black) and aged (red) S-P3MEET at $25{ }^{\circ} \mathrm{C}$. Inset: Photos of fresh (left) and aged (right) S-P3MEET diluted in a) acetone and b) IPW solvent mixture, respectively. which might be beneficial to future degradation/stability studies on a variety of other solution-processed polymers, a comprehensive comparison of fresh and aged S-P3MEET is performed.

The particle sizes of both materials in solution were determined first using the dynamic light scattering method [44]. The resulting size distributions are shown in Fig. 3. As seen, fresh S-P3MEET only shows small clusters with diameter smaller than $700 \mathrm{~nm}$, whereas for aged S-P3MEET, a second peak over $3000 \mathrm{~nm}$ is also present (mean diameter of $5560 \mathrm{~nm}$ ). These larger agglomerates represent almost half of the total polymer volume in the sample. We suspect that the appearance of $\sim 5560 \mathrm{~nm}$ large clusters in the aged S-P3MEET dispersions is attributed to the agglomeration of small S-P3MEET particles. The fact that inhomogeneous/unstable solutions are also observed by diluting aged S-P3MEET into either acetone or IPW solvent mixture (inset of Fig. 3) is another clear indication of in-solution agglomeration. Fresh S-P3MEET dispersions, on the other hand, remain homogeneous with dilution.

We expect that this variation in particle size will result in different rheological behaviors, which again affect film formation/morphology and thereby device performance [45, 46]. In order to elucidate this effect, rheological measurements on fresh and aged S-P3MEET solutions were performed using a rheometer with a cone and plate geometry. The dispersions were directly taken from bottles without dilution. The viscosity changes as a function of shear rate are shown in Fig. 4. For reference, viscosity vs. shear rate is also displayed for a blend of PEDOT:PSS that is commonly used for hole transport layers in organic electronic devices. It can be seen that aged S-P3MEET is two times more viscous than the fresh solution. Both fresh S-P3MEET and PEDOT:PSS exhibit a typical Newtonian fluid behavior where the viscosity is independent of the shear rate. This Newtonian behavior is reported to restrict printability of materials such as PEDOT:PSS, but can be tuned by careful choice of surfactants and additives [45]. By comparison, aged S-P3MEET is found to be a non-Newtonian fluid characterized by a shear-thinning behavior. This shear-thinning behavior is primarily attributed to the formation of aggregates and

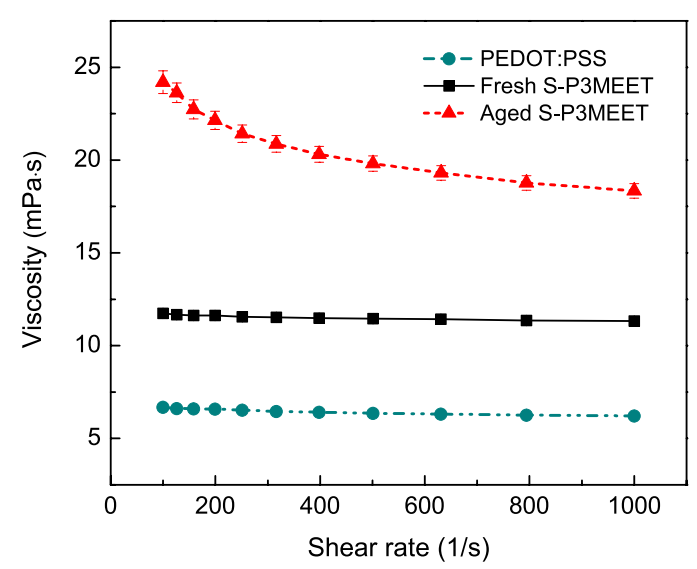

Figure 4: The variation of viscosity with shear rate for PEDOT:PSS (cyan), fresh (black) and aged (red) S-P3MEET solutions at $25^{\circ} \mathrm{C}$. 
Table 1: Summarized zeta potential and particle size results of aged and fresh S-P3MEET with the presence of acid/base/salt/heat.

\begin{tabular}{|c|c|c|c|c|c|c|}
\hline & Aged S-P3MEET & Fresh S-P3MEET & $+\mathrm{HCl}$ & $+\mathrm{NaOH}$ & $+\mathrm{NaCl}$ & Heating $\left(110^{\circ} \mathrm{C}\right)$ \\
\hline Zeta potential $(\mathrm{mV})$ & $-50.3 \pm 6.2$ & $-28.0 \pm 9.2$ & $-23.1 \pm 7.0$ & $-46.9 \pm 3.6$ & $-22.8 \pm 4.2$ & $-46.7 \pm 11.7$ \\
\hline \multirow{2}{*}{ Mean size in nm (vol\%) } & $274.3(53.9 \%)$ & $266.8(100 \%)$ & $1230(58.9 \%)$ & $220.1(100 \%)$ & $283.0(43.7 \%)$ & $249.2(18.4 \%)$ \\
\hline & $5560(46.1 \%)$ & & $5478(41.1 \%)$ & & $893.3(56.3 \%)$ & $4764(81.6 \%)$ \\
\hline
\end{tabular}

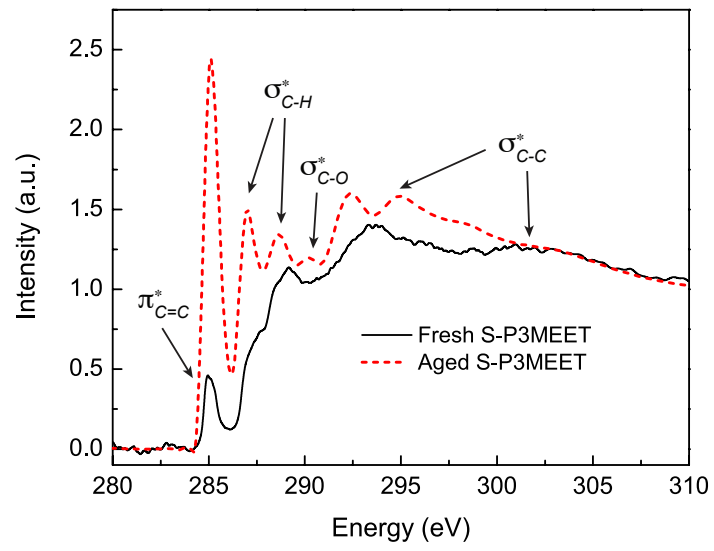

Figure 5: Carbon k-edge NEXAFS spectra of fresh (black) and aged (red) SP3MEET. The spectra were obtained in total electron yield (TEY) mode. The peak assignments are also shown.

S-P3MEET entanglement [47], which again is in good agreement with our interpretation of particle size results where $\sim 46$ vol\% of polymer are found to be large clusters. In addition, studies have also shown that spin-coating of shear-thinning solutions leads to non-uniformities in the film thickness [48, 49].

\subsection{Mechanism of S-P3MEET Aging}

So far, significant differences have been noticed between fresh and aged S-P3MEET. The question then arises as to what causes this aging effect. We first obtained proton nuclear magnetic resonance $\left({ }^{1} \mathrm{H}-\mathrm{NMR}\right)$ spectra of both materials (Supporting Information Fig. S1) but saw only very subtle differences. The only noticeable change is the broadening of the peak around $8.5 \mathrm{ppm}$ for aged S-P3MEET, which corresponds to the backbone proton. We suspect that S-P3MEET is further doped upon aging (self-doped by sulfonate moieties) since the ${ }^{1} \mathrm{H}-\mathrm{NMR}$ shows a hint of stiffening of the backbone. However, additional experimental proof is still needed. Near-edge X-ray absorption fine structure (NEXAFS) spectroscopy is a powerful technique used to investigate the binding energies of core electrons, which thereby enable us to probe the distribution of empty states [50, 21]. Specifically in our case, the delocalized hole states in the highest occupied molecular orbital (HOMO) of S-P3MEET can be detected [42, 43]. The normalized carbon K-edge NEXAFS spectra of fresh and aged S-P3MEET films are obtained and shown in Fig. 5. As can been seen, distinct differences are found between fresh and aged films, especially the first peak at $285.2 \mathrm{eV}$, which is attributed to the $\mathrm{C} 1 \mathrm{~s}(\mathrm{C}=\mathrm{C}) \rightarrow \pi^{*}{ }_{C=C}$ transition of aromatic carbons in the thiophene rings $[42,43]$. This pre-edge peak of aged S-P3MEET increases significantly compared with that of fresh S-P3MEET.

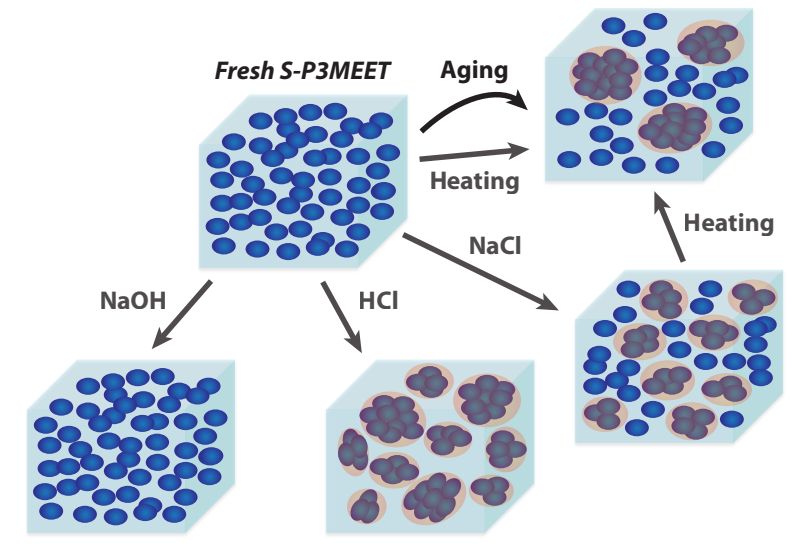

Figure 6: Schematic representation for the S-P3MEET aging/agglomeration.

The increased pre-edge peak is clear evidence that the aged SP3MEET was much more charged locally with higher hole density. Given that neat S-P3MEET is a self-doped polymer without any additives, it is likely that some of the sulfonate groups remain intact in the uncharged form when it is fresh, while aging results in backbone doping by these sulfonate groups over time, generating delocalized hole states. Other than the preedge peak, the peaks above $287 \mathrm{eV}$ mainly correspond to $\mathrm{C} 1 \mathrm{~s}$ $\rightarrow \sigma^{*}$ transitions of PEO side chain. The detailed peak assignments are also shown in Fig. 5. These increased $\sigma^{*}$ peaks upon aging indicate a structural rearrangement of S-P3MEET, causing more side chains arrange at the surface of the material.

If S-P3MEET aging is truly a self-doping process mentioned above, we should be able to duplicate this process by adding external acids (functionalizing similar to the sulfonate groups). In the following experiments, $0.05 \mathrm{~mL}$ of $1.0 \mathrm{M}$ acid and base were added into $1 \mathrm{~mL}$ fresh S-P3MEET solutions, respectively. $\mathrm{NaCl}$ at the same concentration was also added to solution to test the effect of higher ion levels in the solution. Finally, the fresh S-P3MMET solution was heated at $110^{\circ} \mathrm{C}$ for 10 hours in a sealed container to determine whether the aging effect could be replicated in an accelerated experiment (one year is a long time to wait for data). Particle size measurements were performed on the treated solutions and the results are listed in Table 1 and compared to the untreated fresh and aged S-P3MEET solutions. Additionally, zeta potentials were also measured, which allows evaluation of the stability of the dispersions [51]. As can been seen from Table 1, there is a significant difference not only in the particle size, but also the zeta potential when comparing aged S-P3MEET $(-50.5 \pm 6.2 \mathrm{mV})$ and fresh S-P3MEET $(-28.0 \pm 9.2 \mathrm{mV})$. Since the magnitude of the zeta potential represents the electrostatic repulsion between parti- 
cles [52], the increase in zeta potential value (more negative) results in increased physical stability of the dispersion. This explains why fresh S-P3MEET ages. Its zeta potential value of $-28.0 \mathrm{mV}$ is just below the critical value of a stable system ($30 \mathrm{mV}$ ) [53]. In other words, the freshly prepared S-P3MEET holds some degree of stability but eventually agglomerates and segregates out of solution. We assume that increasing the stable lifetime of the solution is the reason that Plextronics Inc. recommended storing the $\mathrm{S}$-P3MEET in a refrigerator.

Closer inspection of the results from Table 1 suggests that the aging process described above is in fact controlled by increased acidic doping. Addition of $\mathrm{HCl}$ to the fresh S-P3MEET solution leads to the formation of larger polymer clusters $(\sim 5500$ $\mathrm{nm}$ ) with similar size scale and vol\% as the aged S-P3MEET solution. It is also apparent that addition of $0.05 \mathrm{ml}$ of $1 \mathrm{M}$ acid yields a higher acidic concentration in general as the zeta potential is $-23.1 \mathrm{eV}$ even after considerable agglomeration. In contrast, adding base to the the S-P3MEET dispersion yielded near identical particles size as the fresh S-P3MEET solution but caused increased stability with zeta potential value of -46.9 $\mathrm{mV}$. This suggests that the dispersion could be stabilized by adding some amount of base. These results are consistent with NEXAFS data where aged S-P3MEET is shown to be more highly charged than fresh S-P3MEET. We also examined the effect of increasing the ionic concentration of the solution by adding an identical concentration of $\mathrm{NaCl}$ and found that the increased ion product of the solution also destabilized the polymer and resulted in aggregation, but with smaller agglomerates than caused by the acidic doping or aging. Finally, heating the fresh S-P3MEET up to $110{ }^{\circ} \mathrm{C}$ leads to a straightforward accelerated aging process with both the particle size and zeta potential similar to the aged S-P3MEET solution. All these processes are summarized in pictorial form in Fig. 6.

\subsection{Effect of External Acidic Additive on Film Properties}

In the previous section, we show significant effects of aging on S-P3MEET and also reveal that the aging process can be accelerated by adding external acid. Our previous studies have also shown that the work function of S-P3MEET film can be easily tuned with addition of PFI [42]. The fact that PFI is acidic causes concerns for the acceleration of aging of the SP3MEET solution and may have an effect on the properties of the resulting films. Therefore, the effects of PFI additive on the electrical and morphological properties of the S-P3MEET films are investigated.

The in-plane $\left(\sigma_{\|}\right)$and out-of-plane $\left(\sigma_{\perp}\right)$ conductivity of $\mathrm{PFI} / \mathrm{S}-\mathrm{P} 3 \mathrm{MEET}$ blend films are shown in Fig. 7a and b, respectively. Both $\sigma_{\perp}$ and $\sigma_{\|}$were measured because of the strong electronic anisotropy demonstrated for hole transport layers $[22,54]$. The $\sigma_{\|}$of fresh S-P3MEET (black squares) shows a continuous decrease upon adding PFI, from $0.1 \mathrm{~S} / \mathrm{cm}$ for neat film to $10^{-4} \mathrm{~S} / \mathrm{cm}$ at $75 \mathrm{wt} \%$ PFI. In contrast, the $\sigma_{\perp}$ is approximately three orders of magnitude lower than $\sigma_{\|}$for pure S-P3MEET and does not show much change over the entire loading range (note the linear scale on the vertical axis). Similarly, anisotropic conductivity was also reported for PEDOT:PSS films [55]. Since the film is already self-doped along
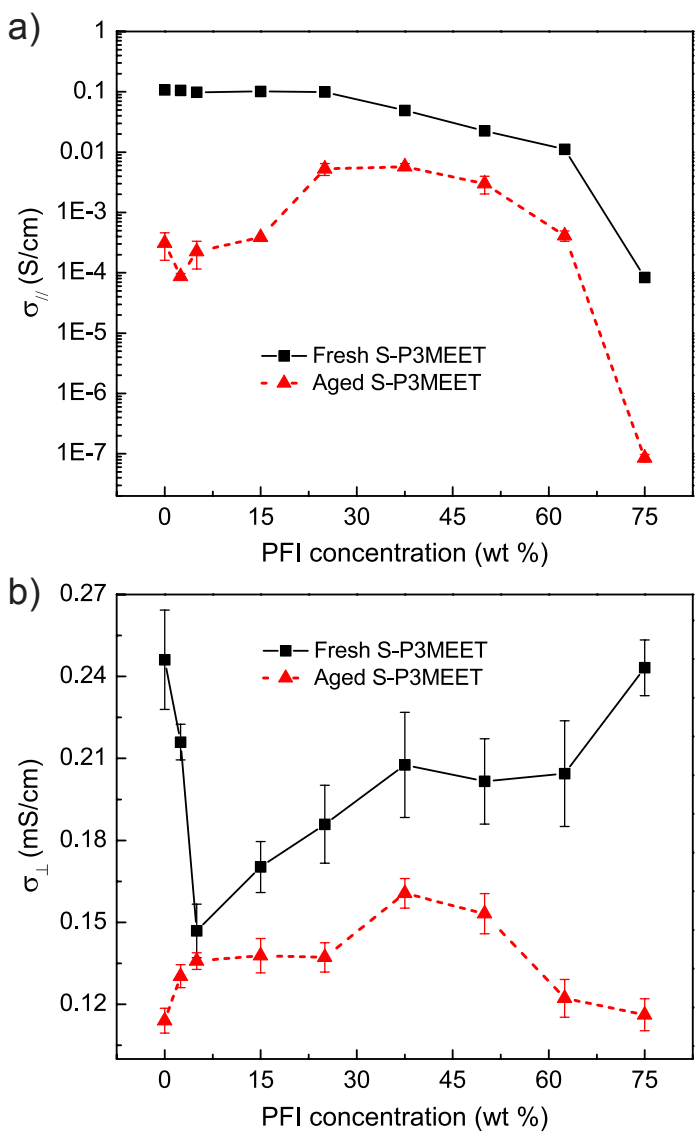

Figure 7: In-plane (a) and out-of-plane (b) conductivity measurements of fresh (black) and aged (red) S-P3MEET/PFI blend films as a function of PFI concentration.

the backbone, the presence of an external additive does not increase the conductivity, but instead has a strong affect on the work function and morphology of the film [42]. Decreased carrier mobility is also expected upon addition of a non-conductive external additive as was observed for other weakly disordered materials at low electric fields [56, 57]. The addition of PFI strongly increases the energetic disorder of the polymer and reduces the density of percolation pathways. There is therefore a tradeoff between increased work function and reduced conductivity in-plane. However, $\sigma_{\perp}$ remains nearly constant even with 75 wt \% PFI, which is the effect that we wish to explore here.

The same conductivity measurements were performed one year later using the same batch of S-P3MEET with very different results. Fig. $7 \mathrm{a}$ and $\mathrm{b}$ also show the changes in conductivity for aged S-P3MEET films at various PFI concentrations (red lines). As can been seen, $\sigma_{\|}$of aged S-P3MEET is about three orders of magnitude lower than that of fresh S-P3MEET for a neat sample, in spite of the fact that aged S-P3MEET is more highly doped as shown in Fig. 5. The $\sigma_{\perp}$ is also lower with aging to some extent. In addition, the PFI concentration dependent conductivity also shows a different trend. Instead of decreasing, both $\sigma_{\|}$and $\sigma_{\perp}$ show a initial increase and then drop once the PFI loading reaches $25 \sim 35 \mathrm{wt} \%$. The reduction of $\sigma_{\|}$but not $\sigma_{\perp}$ for fresh S-P3MEET in particular drew our 


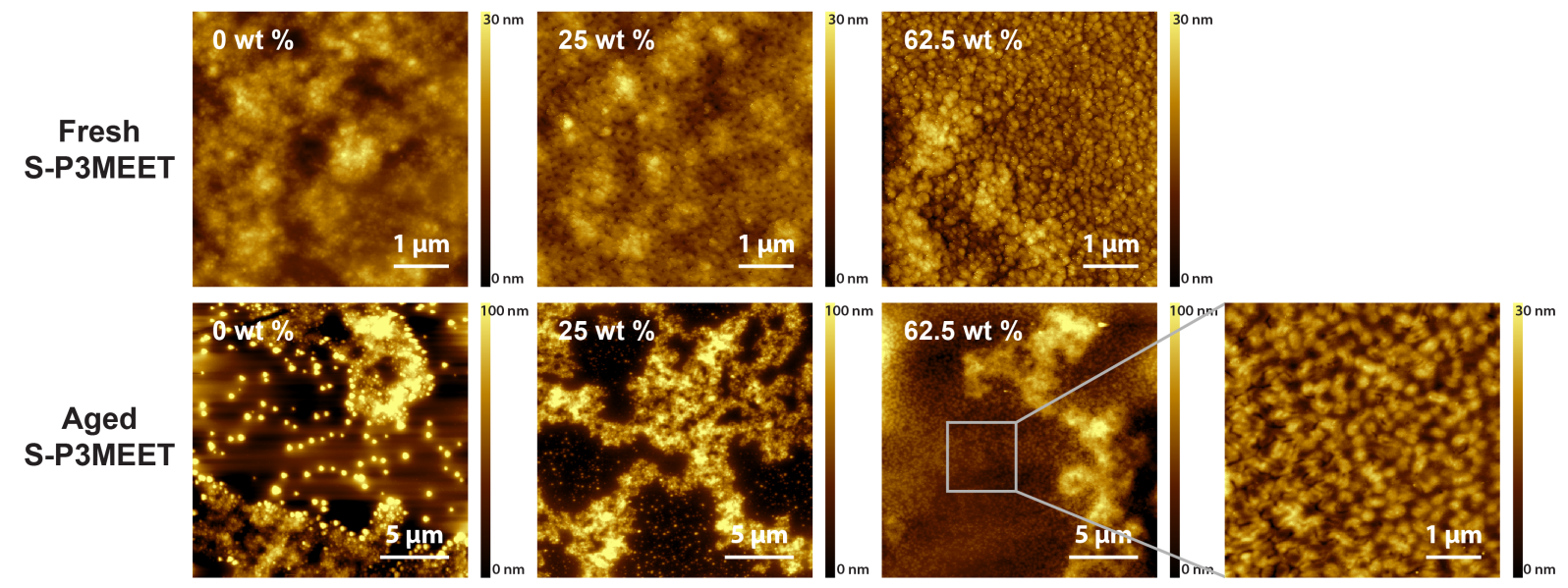

Figure 8: Topography images of PFI blended fresh (top) and aged (bottom) S-P3MEET films obtained with tapping-mode AFM. Note the different scale between two samples.

attention because with $0.75 \mathrm{wt} \%$ PFI this mixture has a work function of $6.0 \mathrm{eV}$ and shows excellent hole extraction for OPV polymers with low lying HOMO levels [42]. In addition, low $\sigma_{\|}$ and high $\sigma_{\perp}$ is ideal for application in pixelated OLED displays due to reduced crosstalk between neighboring pixels $[55,58]$.

To understand the morphological origin of the effect of PFI additive on the S-P3MEET, the surface morphology was investigated using atomic force microscopy (AFM). AFM images of both fresh and aged S-P3MEET at selected PFI concentrations are shown in Fig. 8. The full PFI concentration series of topographic images and roughness values can be found in the Supporting Information (Fig. S2-3 and S4, respectively). As can be seen from Fig. 8, the surface of pure fresh S-P3MEET is relatively smooth and homogeneous compared with highly PFI loaded films. With increased PFI concentration, the domains of S-P3MEET are increasingly isolated and surrounded by PFI, which can be seen clearly at $62.5 \mathrm{wt} \%$ loading. Although micro-level agglomerates are obvious from the topography at high loading level, fresh S-P3MEET is still a continuous film. The phase images at high PFI concentration in Fig. S2 also show two clear separate phases, where islands of darker phase are surrounded by lighter phases. A similar phenomenon has also been reported in the PEDOT:PSS by showing that PEDOTrich clusters are separated by lamellas of PSS [55, 59]. This is consistent with our interpretation of the conductivity results. Addition of PFI increases disorder of polymers. In addition, as an ionically conductive polymer, PFI is less conductive than S-P3MEET. This phase separation leads to low percolation of S-P3MEET, which explains its decreased in-plane conductivity upon loading. On the other hand, since these vertical columns still provide out-of-plane pathways for conduction, the $\sigma_{\perp}$ values, therefore, do not show significant change.

In contrast, the AFM images of aged S-P3MEET film show completely different surface morphology. Due to its larger feature size, the AFM images are obtained at $20 \times 20 \mu \mathrm{m}^{2}$. The neat aged S-P3MEET film contains sections with large and small clusters and also holes in the film in which there is no S-P3MEET, only bare substrate. This discontinuity across the film results in decreased $\sigma_{\|}$compared to fresh S-P3MEET as expected. The result shown here is also in good agreement with particle size results. Half of the small S-P3MEET particles (the $274 \mathrm{~nm}$ population) agglomerate to form larger clusters (the $5560 \mathrm{~nm}$ population), which causes the polymer to crash out of solution and thereby unable to achieve continuous films. Interestingly, with moderate PFI loading, a cluster network starts to form, which can be clearly seen at $25 \mathrm{wt} \%$ PFI. This network percolates throughout the film and thereby provides in-plane pathways for conduction, resulting in enhanced $\sigma_{\|}$. Further increasing PFI loading facilitates the formation of a complete film but reduces $\sigma_{\|}$. A zoomed in image of the aged S-P3MEET in the smooth sections reveals PFI and S-P3MEET phase segregated structures as in the fresh S-P3MEET films. The raised and irregularly shaped domains are from the larger clusters that form in solution.

To sum up, the presence of PFI in the fresh S-P3MEET film shows a significant decrease in the in-plane conductivity, which is expected based on the AFM results showing separation of SP3MEET agglomerates with PFI between. The vertical conductivity, however, shows little change. Since PFI is acidic and we showed in section 3.2 that addition of acid to the solution accelerates the aging and agglomeration of S-P3MEET, PFI should only be mixed into solution shortly before coating. In comparison, the aged S-P3MEET solution was shown to be more highly self-doped, but does not form continuous films and therefore has considerably lower in-plane conductivity. This complex aging process and similar solution degradation processes may explain some of the high variability in organic device characteristics when comparing results between different research groups.

\section{Conclusions}

In conclusion, substantial differences between fresh and aged S-P3MEET were observed. The fresh S-P3MEET solution is homogenous and behaves as a typical Newtonian fluid. In contrast, the aged S-P3MEET solution shows large agglomerates 
and shear-thinning rheological behavior, which results in nonuniform spin-coated films. NEXAFS results reveal that aged S-P3MEET exhibits a higher charging level compared to fresh S-P3MEET and is consistent with results from acid/base experiments. The aging process of fresh S-P3MEET can also be accelerated by the application of heat to the solution.

Previous reports of using a PFI additive to control the SP3MEET work function were re-examined because of the concern that the acidic PFI additive may accelerate the S-P3MEET aging process. Here we compared in-plane and out-of-plane conductivity measurements at various PFI concentrations to the AFM topography of the films. We found that PFI additive had little effect on the out-of-plane conductivity of the fresh S-P3MEET films but reduced the in-plane conductivity by several orders of magnitude. Therefore, care must be taken that the S-P3MEET solutions are fresh and that the PFI is not allowed to stabilize the solution. Understanding the stability of dispersions will allow for the development of more stable materials for solution processing as well as minimizing undesired inconsistency in performance.

\section{Acknowledgement}

This research project was supported by the U.S. Department of Energy, Office of Basic Energy Sciences, Division of Materials Sciences and Engineering, under Award DESC0010419. The NEXAFS work was performed in collaboration under the auspices of the U.S. Department of Energy by Lawrence Livermore National Laboratory under Contract DEAC52-07NA27344. We would like to thank Elke Arrenholz and Alpha N'Diaye (ALS) for user support and training, Prof. Nitin Nitin (UC Davis) for help of the particle size and zeta potential measurements, and Dr. Charles F. Shoemaker (UC Davis) for helping with the rheological measurements.

\section{References}

[1] S. R. Forrest, The path to ubiquitous and low-cost organic electronic appliances on plastic, Nature 428 (6986) (2004) 911-918.

[2] F. C. Krebs, T. D. Nielsen, J. Fyenbo, M. Wadstrom, M. S. Pedersen, Manufacture, integration and demonstration of polymer solar cells in a lamp for the "lighting africa" initiative, Energy Environ. Sci. 3 (2010) $512-525$.

[3] Y. Liu, J. Zhao, Z. Li, C. Mu, W. Ma, H. Hu, K. Jiang, H. Lin, H. Ade, H. Yan, Aggregation and morphology control enables multiple cases of high-efficiency polymer solar cells, Nat. Commun. 5 (5293).

[4] Q. Zhang, B. Li, S. Huang, H. Nomura, H. Tanaka, C. Adachi, Efficient blue organic light-emitting diodes employing thermally activated delayed fluorescence, Nat. Photonics 8 (4) (2014) 326-332.

[5] Q. Zhang, D. Tsang, H. Kuwabara, Y. Hatae, B. Li, T. Takahashi, S. Y. Lee, T. Yasuda, C. Adachi, Nearly 100electroluminescent devices employing pure organic emitters, Adv. Mater. 27 (12) (2015) 2096-2100.

[6] M. Jørgensen, K. Norrman, F. C. Krebs, Stability/degradation of polymer solar cells, Sol. Energy Mater. Sol. Cells 92 (7) (2008) 686-714.

[7] M. Jørgensen, K. Norrman, S. A. Gevorgyan, T. Tromholt, B. Andreasen, F. C. Krebs, Stability of polymer solar cells, Adv. Mater. 24 (5) (2012) 580-612.

[8] F. C. Krebs, Fabrication and processing of polymer solar cells: A review of printing and coating techniques, Sol. Energy Mater. Sol. Cells 93 (4) (2009) 394-412.
[9] F. C. Krebs, J. E. Carlé, N. Cruys-Bagger, M. Andersen, M. R. Lilliedal, M. A. Hammond, S. Hvidt, Lifetimes of organic photovoltaics: photochemistry, atmosphere effects and barrier layers in ito-mehppv:pcbmaluminium devices, Sol. Energy Mater. Sol. Cells 86 (4) (2005) 499-516.

[10] K. Kawano, R. Pacios, D. Poplavskyy, J. Nelson, D. D. Bradley, J. R. Durrant, Degradation of organic solar cells due to air exposure, Sol. Energy Mater. Sol. Cells 90 (20) (2006) 3520-3530.

[11] K. Norrman, M. V. Madsen, S. A. Gevorgyan, F. C. Krebs, Degradation patterns in water and oxygen of an inverted polymer solar cell, J. Am. Chem. Soc. 132 (47) (2010) 16883-16892.

[12] B. H. Cumpston, K. F. Jensen, Photooxidative stability of substituted poly(phenylene vinylene) (ppv) and poly(phenylene acetylene) (ppa), J. Appl. Polym. Sci. 69 (12) (1998) 2451-2458.

[13] J. Alstrup, K. Norrman, M. Jørgensen, F. C. Krebs, Lifetimes of organic photovoltaics: Design and synthesis of single oligomer molecules in order to study chemical degradation mechanisms, Sol. Energy Mater. Sol. Cells 90 (17) (2006) 2777-2792.

[14] F. Padinger, T. Fromherz, P. Denk, C. Brabec, J. Zettner, T. Hierl, N. S. Sariciftci, Degradation of bulk heterojunction solar cells operated in an inert gas atmosphere: a systematic study, Synth. Met. 121 (2001) 16051606.

[15] Y. Kim, A. M. Ballantyne, J. Nelson, D. D. Bradley, Effects of thickness and thermal annealing of the pedot:pss layer on the performance of polymer solar cells, Org. Electron. 10 (1) (2009) 205-209.

[16] M. Ishii, Y. Taga, Influence of temperature and drive current on degradation mechanisms in organic light-emitting diodes, Appl. Phys. Lett. 80 (18) (2002) 3430-3432.

[17] M. Lögdlund, J. L. Brédas, Theoretical studies of the interaction between aluminum and poly(pphenylenevinylene) and derivatives, J. Chem. Phys. 101 (5) (1994) 4357-4364.

[18] H. Antoniadis, B. Hsieh, M. Abkowitz, S. Jenekhe, M. Stolka, Photovoltaic and photoconductive properties of aluminum/poly(p-phenylene vinylene) interfaces, Synth. Met. 62 (3) (1994) 265-271.

[19] C. Melzer, V. V. Krasnikov, G. Hadziioannou, Organic donor/acceptor photovoltaics: The role of c60/metal interfaces, Appl. Phys. Lett. 82 (18) (2003) 3101-3103.

[20] K. Norrman, F. C. Krebs, Lifetimes of organic photovoltaics: Using tofsims and 1802 isotopic labelling to characterise chemical degradation mechanisms, Sol. Energy Mater. Sol. Cells 90 (2) (2006) 213-227.

[21] D. M. Huang, S. A. Mauger, S. Friedrich, S. J. George, D. DumitriuLaGrange, S. Yoon, A. J. Moulé, The consequences of interface mixing on organic photovoltaic device characteristics, Adv. Funct. Mater. 21 (2011) 1657-1665.

[22] S. A. Mauger, L. Chang, C. W. Rochester, A. J. Moulé, Directional dependence of electron blocking in pedot:pss, Org. Electron. 13 (11) (2012) 2747-2756.

[23] X. Yang, J. K. J. van Duren, R. A. J. Janssen, M. A. J. Michels, J. Loos, Morphology and thermal stability of the active layer in poly(p-phenylenevinylene)/methanofullerene plastic photovoltaic devices, Macromolecules 37 (6) (2004) 2151-2158.

[24] L. Chang, H. W. A. Lademann, J. B. Bonekamp, K. Meerholz, A. J. Moulé, Effect of trace solvent on the morphology of p3ht:pcbm bulk heterojunction solar cells, Adv. Funct. Mater. 21 (10) (2011) 1779-1787.

[25] B. Lüssem, M. Riede, K. Leo, Doping of organic semiconductors, Phys. Status Solidi A 210 (1) (2013) 9-43.

[26] J. Li, C. W. Rochester, I. E. Jacobs, S. Friedrich, P. Stroeve, M. Riede, A. J. Moulé, Measurement of small molecular dopant f4tcnq and c60f36 diffusion in organic bilayer architectures, ACS Appl. Mater. Interfaces 7 (51) (2015) 28420-28428.

[27] J. Li, G. Zhang, D. M. Holm, I. E. Jacobs, B. Yin, P. Stroeve, M. Mascal, A. J. Moulé, Introducing solubility control for improved organic p-type dopants, Chem. Mater. 27 (16) (2015) 5765-5774.

[28] Y. Vaynzof, D. Kabra, L. Zhao, L. L. Chua, U. Steiner, R. H. Friend, Surface-directed spinodal decomposition in poly[3-hexylthiophene] and c61-butyric acid methyl ester blends, ACS Nano 5 (1) (2011) 329-336.

[29] N. Grossiord, J. M. Kroon, R. Andriessen, P. W. Blom, Degradation mechanisms in organic photovoltaic devices, Org. Electron. 13 (3) (2012) 432-456.

[30] N. Li, F. Machui, D. Waller, M. Koppe, C. J. Brabec, Determination of phase diagrams of binary and ternary organic semiconductor blends for organic photovoltaic devices, Sol. Energy Mater. Sol. Cells 95 (12) (2011) 
3465-3471.

[31] F. Machui, P. Maisch, I. Burgués-Ceballos, S. Langner, J. Krantz, T. Ameri, C. J. Brabec, Classification of additives for organic photovoltaic devices, ChemPhysChem 16 (6) (2015) 1275-1280.

[32] F. C. Krebs, S. A. Gevorgyan, B. Gholamkhass, S. Holdcroft, C. Schlenker, M. E. Thompson, B. C. Thompson, D. Olson, D. S. Ginley, S. E. Shaheen, H. N. Alshareef, J. W. Murphy, W. J. Youngblood, N. C. Heston, J. R. Reynolds, S. Jia, D. Laird, S. M. Tuladhar, J. G. Dane, P. Atienzar, J. Nelson, J. M. Kroon, M. M. Wienk, R. A. Janssen, K. Tvingstedt, F. Zhang, M. Andersson, O. Inganäs, M. Lira-Cantu, R. de Bettignies, S. Guillerez, T. Aernouts, D. Cheyns, L. Lutsen, B. Zimmermann, U. Würfel, M. Niggemann, H.-F. Schleiermacher, P. Liska, M. Grätzel, P. Lianos, E. A. Katz, W. Lohwasser, B. Jannon, A round robin study of flexible large-area roll-to-roll processed polymer solar cell modules, Sol. energy mater. sol. cells 93 (11) (2009) 1968-1977.

[33] M. Koppe, C. J. Brabec, S. Heiml, A. Schausberger, W. Duffy, M. Heeney, I. McCulloch, Influence of molecular weight distribution on the gelation of p3ht and its impact on the photovoltaic performance, Macromolecules 42 (13) (2009) 4661-4666.

[34] B. G. Ranby, J. F. Rabek, Photodegradation, Photo-oxidation, and Photostabilization of Polymers: Principles and Applications, John Wiley, 1975.

[35] H. H. G. Jellinek, Aspects of degradation and stabilization of polymers, Elsevier Scientific Pub. Co., 1978.

[36] A. Elschner, S. Kirchmeyer, W. Lovenich, U. Merker, K. Reuter, PEDOT: principles and applications of an intrinsically conductive polymer, CRC Press, 2010.

[37] S. A. Mauger, A. J. Moulé, Characterization of new transparent organic electrode materials, Org. Electron. 12 (11) (2011) 1948-1956.

[38] T.-C. Tsai, H.-C. Chang, C.-H. Chen, Y.-C. Huang, W.-T. Whang, A facile dedoping approach for effectively tuning thermoelectricity and acidity of pedot:pss films, Org. Electron. 15 (3) (2014) 641-645.

[39] F. Kong, C. Liu, H. Song, J. Xu, Y. Huang, H. Zhu, J. Wang, Effect of solution ph value on thermoelectric performance of free-standing pedot:pss films, Synth. Met. 185-186 (2013) 31-37.

40] X. Crispin, F. L. E. Jakobsson, A. Crispin, P. C. M. Grim, P. Andersson, A. Volodin, C. van Haesendonck, M. Van der Auweraer, W. R. Salaneck, M. Berggren, The origin of the high conductivity of poly $(3,4$ ethylenedioxythiophene)poly(styrenesulfonate) (pedot-pss) plastic electrodes, Chem. Mater. 18 (18) (2006) 4354-4360.

[41] J. Huang, P. Miller, J. Wilson, A. deMello, J. deMello, D. Bradley, Investigation of the effects of doping and post-deposition treatments on the conductivity, morphology, and work function of poly $(3,4-$ ethylenedioxythiophene)/poly(styrene sulfonate) films, Adv. Funct. Mater. 15 (2) (2005) 290-296.

[42] S. A. Mauger, J. Li, O. T. Ozmen, A. Y. Yang, S. Friedrich, M. D. Rail, L. A. Berben, A. J. Moulé, High work-function hole transport layers by self-assembly using a fluorinated additive, J. Mater. Chem. C 2 (2014) $115-123$.

[43] J. Li, C. W. Rochester, I. E. Jacobs, E. W. Aasen, S. Friedrich, P. Stroeve, A. J. Moulé, The effect of thermal annealing on dopant site choice in conjugated polymers, Org. Electron. 33 (2016) 23-31.

[44] B. J. Berne, R. Pecora, Dynamic light scattering: with applications to chemistry, biology, and physics, Courier Corporation, 2000.

[45] M. M. Voigt, R. C. Mackenzie, S. P. King, C. P. Yau, P. Atienzar, J. Dane, P. E. Keivanidis, I. Zadrazil, D. D. Bradley, J. Nelson, Gravure printing inverted organic solar cells: the influence of ink properties on film quality and device performance, Sol. Energy Mater. Sol. Cells 105 (2012) 77-85.

[46] T. R. Andersen, H. F. Dam, M. Hosel, M. Helgesen, J. E. Carle, T. T. Larsen-Olsen, S. A. Gevorgyan, J. W. Andreasen, J. Adams, N. Li, F. Machui, G. D. Spyropoulos, T. Ameri, N. Lemaitre, M. Legros, A. Scheel, D. Gaiser, K. Kreul, S. Berny, O. R. Lozman, S. Nordman, M. Valimaki, M. Vilkman, R. R. Sondergaard, M. Jorgensen, C. J. Brabec, F. C. Krebs, Scalable, ambient atmosphere roll-to-roll manufacture of encapsulated large area, flexible organic tandem solar cell modules, Energy Environ. Sci. 7 (2014) 2925-2933.

[47] S. Comba, R. Sethi, Stabilization of highly concentrated suspensions of iron nanoparticles using shear-thinning gels of xanthan gum, Water Res. 43 (15) (2009) 3717-3726.

[48] C. Lawrence, W. Zhou, Spin coating of non-newtonian fluids, J. NonNewtonian Fluid Mech. 39 (2) (1991) 137-187.

[49] S. A. Jenekhe, S. B. Schuldt, Coating flow of non-newtonian fluids on a flat rotating disk, Ind. Eng. Chem. Fundam. 23 (4) (1984) 432-436.

[50] B. Watts, S. Swaraj, D. Nordlund, J. Lüning, H. Ade, Calibrated nexafs spectra of common conjugated polymers, J. Chem. Phys. 134 (2) (2011) 024702 .

[51] R. J. Hunter, Zeta potential in colloid science: principles and applications, Academic Press, 1981

[52] B. P. Singh, R. Menchavez, C. Takai, M. Fuji, M. Takahashi, Stability of dispersions of colloidal alumina particles in aqueous suspensions, $\mathrm{J}$. Colloid Interface Sci. 291 (1) (2005) 181-186.

[53] C. Freitas, R. H. Müller, Effect of light and temperature on zeta potential and physical stability in solid lipid nanoparticle $\left(\sin { }^{\mathrm{TM}}\right)$ dispersions, Int. J. Pharm. 168 (2) (1998) 221-229.

[54] K. van de Ruit, I. Katsouras, D. Bollen, T. van Mol, R. A. J. Janssen, D. M. de Leeuw, M. Kemerink, The curious out-of-plane conductivity of pedot:pss, Adv. Funct. Mater. 23 (46) (2013) 5787-5793.

[55] A. M. Nardes, M. Kemerink, R. A. J. Janssen, J. A. M. Bastiaansen, N. M. M. Kiggen, B. M. W. Langeveld, A. van Breemen, M. M. de Kok, Microscopic understanding of the anisotropic conductivity of pedot : Pss thin films, Adv. Mater. 19 (9) (2007) 1196-1200.

[56] X. Jiang, Y. Harima, K. Yamashita, Y. Tada, J. Ohshita, A. Kunai, Dopinginduced change of carrier mobilities in poly(3-hexylthiophene) films with different stacking structures, Chem. Phys. Lett. 364 (5-6) (2002) 616620

[57] V. I. Arkhipov, P. Heremans, E. V. Emelianova, H. Bässler, Effect of doping on the density-of-states distribution and carrier hopping in disordered organic semiconductors, Phys. Rev. B 71 (2005) 045214

[58] A. Cravino, P. Schilinsky, C. Brabec, Characterization of organic solar cells: the importance of device layout, Adv. Funct. Mater. 17 (18) (2007) 3906-3910.

[59] S. Timpanaro, M. Kemerink, F. Touwslager, M. D. Kok, S. Schrader, Morphology and conductivity of pedot/pss films studied by scanning tunneling microscopy, Chem. Phys. Lett. 394 (4-6) (2004) 339-343. 


\section{Graphical abstract}

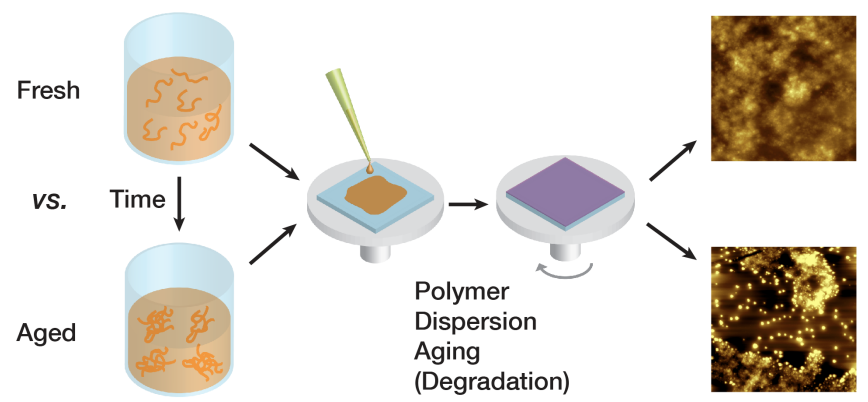

